\title{
NOVAS REFLEXÕES SOBRE A "IDÉIA DA AMÉRICA LATINA": a direita, a esquerda e a opção descolonial
}

\author{
WalterD. Mignolo*
}

\begin{abstract}
Este texto tem um caráter específico de debate, retomado pelo autor em função de resenhas e entrevistas realizadas sobre o seu livro The Idea of Latin America, publicado em 2005. Inicia demonstrando como as narrativas diversificadas da história da colonização são plurais, mas, ao serem difundidas, unificam-se em narrativas globais de caráter universal, como efeito de processos de totalidade. Para o autor, essa diversidade de forças históricas caladas, mas vivas, hoje se expõem sem perspectiva de retorno ao passado. Nesse sentido, ele fala do projeto modernidade e colonialismo, de descolonizar o conhecimento, respondendo e aprofundando diversos aspectos paradoxais postos pelo debate de seu livro, como o diálogo entre movimentos e pensamentos de emancipação que surgem no centro do sistema-mundo. Com isso, não pretende fechar-se ao debate, mas, ao contário, busca atualizar e avançar nessas questões da diferença e das populações não homogêneas de uma perspectiva de futuro e de uma perspectiva de um conhecimento e práticas pluri-versalistas.

PALAVRAS-CHAVE: modernidade, emancipação, diferença, descolonização do pensamento, América Latina.
\end{abstract}

\section{INTRODUÇÃO}

O Novo Mundo e a América são invenções européia-cristãs, cujos agentes foram as monarquias e, em seguida, os estados-nacionais do Atlântico. A formação histórica do mundo moderno-colonial resultou das ações e das narrativas produzidas basicamente em quatro das seis línguas modernas imperiais: português, castelhano, francês e inglês. Ao relermos, hoje, a seção sobre o colonialismo, no clássico livro de Adam Smith The Wealth of Nations (1776), aprendemos - a partir do ponto de vista dos interesses britânicos, que Smith nos concede de forma afetiva e intelectual - como, ao longo dos séculos XVI e XVII, vão se configurando certas "brigas de família" entre Castela, Portugal, Holanda e França, que, ao serem narradas, impressas e difundidas como nenhuma outra narrativa tinha podido fazê-lo naquele momento, convertem-se numa narrativa global (alguns diriam,

\footnotetext{
* Professor de Literatura na Duke University - Estados Unidos.wmignolo@duke.edu
}

inclusive, de caráter universal). Esse processso é um tanto similar à narrativa do baseball dos Estados Unidos, cujos campeonatos anuais se anunciam como se fossem a copa do mundo, em torneios que, no melhor dos casos, além dos Estados Unidos, só há, no máximo, uma equipe canadense.

Ao lado de Smith, estava - em Londres - o africano liberto Ottobah Cugoano. Em seu relato, Thoughts and Sentiments on the Evil of Slavery (1786), não fazia qualquer diferença entre as cinco monarquias que disputavam as possessões e as riquezas da América e convertiam os africanos numa mercadoria a mais. Para Adam Smith, o livre comércio era, sem dúvida, o motor da prosperidade; assim, por exemplo, ele nos conta, entre as muitas histórias e exemplos que apóiam seu argumento, que:

Rum is a very important article in the trade which the Americans carry on the coast of Africa, from which they bring back negroes slaves in return (1976 [1776], v. 2, p.91).

Cugoano tinha outra imagem, porque não vivenciava - como Smith - os interesses e a histó- 
ria da Grã Bretanha, mas sentia na pele e a história de africanos capturados, transportados ao Novo Mundo e escravizados:

Nothing else can be conceived, but that the power of infernal wickedness has so reigned and pervaded over the enlightened nations as to infatuate and lead on the great men, and the kings of Europe, to promote and establish such a horrible traffic of wiknedness as the African slave trade and the West-India slavery, and thereby to bring themselves under the guilty responsibility of such awful inequity (Cugoano, 1999 [1786], p.81).

O "espírito do capitalismo" (cuja fundação histórica se localiza nas mudanças radicais introduzidas pela abertura da economia do Atlântico, no século XVI), não parece estar ligado à ascética protestante e à secularização da chamada, como foi proposto por Max Weber, mas a uma ética da rapinagem que prevalece, de forma ainda mais ampla, hoje em dia. Por essa razão, a obra de Smith continua sendo um livro de cabeceira para os pensadores liberais, enquanto que a ética do direito à vida, que Cugoano defende, passou a ser curiosidade étnica do multiculturalismo.

Tudo isso é parte do processo de invenção da América (O’Gorman). Nesse processo, ademais da escravidão, fortes organizações sociais, como o Tawantinsuyu e Anahuac, e territorialidades, como a de Abya-Yala, foram sendo relegadas ao passado. Sem dúvida, a população indígena que vai de Tawatinsuyu a Anahuac, suas zonas intermediárias, mais "seus nortes e seus suis", ou as populações indígenas do Caribe, tal como os arahuacos e os taínos, não eram homogêneas. Tampouco eram homogêneas as multidões de africanos roubados e arrancados de seus reinos e principados. Foram arrebatados de distintos reinados, falavam línguas diferentes e tinham vários tipos de crenças. Tampouco aqueles que chegaram da Europa formavam uma massa homogênea. Eram cristãos, sim, mas de ordens monásticas de diferentes tipos. Com o decorrer do tempo, não somente provinham da Península Ibérica, mas também da França, Holanda e Inglaterra. A América do Sul, nesse processo, ilustra cada vez mais o que seria entendido como a tradição e o subdesenvolvimento. A América do Norte, em contrapartida, encarnará o espírito do capitalismo, tanto na versão de Weber como na anterior de Smith. Sem dúvida que, nesse processo, haverá também focos do espírito capitalista na América do Sul e outros focos de indiferença.

Contudo, a difusão do mercado do livro e das idéias, que fez de Smith um clássico e de Cugoano uma curiosidade para espíritos bem pensantes, pode encobrir, porém não enterrar e desterrar, essas particularidades. Enquanto os europeus letrados, pessoas de governos, viajantes, etc., nadavam, direta ou indiretamente, nas fontes gregas e romanas, no latim e no grego, o mesmo não acontecia com a diversidade e variedade indígena e africana. Para os europeus, o wolof e o bambara, o aymara, o quechua ou o tojolabal eram idiomas tão estranhos como o latim e o grego o eram também para africanos e indígenas. No entanto, conhecemos a história: a elite crioula de descendência européia, a elite mestiça de espírito europeizado e a população migrante européia dos fins do século XIX em diante mantiveram viva a chama moderno-colonial.

Hoje, essas forças históricas, caladas durante séculos, porém nunca apagadas, chegaram a um ponto que não tem retorno. Não sei qual será o destino do governo de Evo Morales. No entanto, já não é possível voltar atrás no passo que foi dado. Não sei qual será o destino do socialismo do século XXI, mas tenho a impressão de que tampouco haverá retorno nem ao socialismo castrista nem ao franco neoliberalismo que golpeou América Latina desde Augusto Pinochet e Carlos Sául Menem a Gonzálo Sánchez de Losada. A elite petroleira da Venezuela já perdeu definitivamente o que possuía antes da chegada de Hugo Chávez. Por tudo isso, é necessário atender ao nível ontológico da idéia da América Latina, e prestar atenção além do mais ao nível ôntico. Isto é, não aceitar a América Latina como uma coisa natural e contar histórias do que lá acontece, esquecendo que tudo que lá ocorre tem sua razão de ser na história imperialcolonial de como a América Latina foi constituída. Os 40 milhões de latinos presentes hoje, 
nos Estados Unidos, mostram outra cara da sua latinidade: não mais a européia, branca, mas a latinidade de cor. Não sei se Barack Obama será eleito presidente. O que não se pode evitar é que também nos Estados Unidos - com as devidas diferenças, entre a América anglo-saxã e a América considerada como latina - chegou-se a um ponto sem retorno. Não menos importante é o fato, nas Américas, de duas mulheres brancas, e uma mulher branca, nos Estados Unidos, já serem presidentas e (ou) pleitearem a carreira presidencial.É também certo que nem toda pessoa de cor é dissidente, e muitas têm o direito de optar pela assimilação e votar pelo partido republicano. No entanto, é difícil imaginar que $100 \%$ das pessoas de cor se assimilarão às formas de vida dos "anglos brancos"; assim como é também difícil imaginar que todos os "anglos brancos" aceitarão e reproduzirão formas de vida que herdaram, mas que já não são suas.

Vou ilustrar essas questões a partir de resenhas, críticas, entrevistas e comentários que surgem de novas reflexões sobre meu livro La Idea de América Latina.

Pelo que conheço, a versão original de The Idea of Latin America (2005a) e sua tradução para o castelhano La idea de América Latina (2007) receberam duas resenhas e duas entrevistas de considerável extensão. Tanto as resenhas como as entrevistas provocam e convidam a um debate que busco dar continuidade com estas reflexões.

Cronologicamente, a primeira resenha ${ }^{1}$ foi a do historiador argentino Ricardo Salvatore (2006), intitulada A Post-Occidentalist Manifesto, publicada em A Contracorriente, revista de História Social e Literatura na América Latina. Com Salvatore temos uma relação amistosa e intelectual de longa data, ainda que com as diferenças entre um histo-

${ }^{1}$ Resenhas breves foram publicadas por Robert B. Kent (2007), que colocou o livro em circulação entre geógrafos e na área da geografia humana. E, no âmbito da língua e literatura, a resenha de Susan Castillo (2007) é única e informativa. riador e um semiólogo, meio filósofo e meio historiador. A resenha de Salvatore é coerente com o argumento do livro, e o leitor de sua resenha não será guiado por falsos caminhos. Ele é também generoso, ao mesmo tempo em que sublinha aspectos do argumento que são relevantes para mim. Salvatore sublinha que La idea de América Latina é um verdadeiro manifesto para a descolonização do conhecimento nas e sobre as Américas (Salvatore, 2006, p.130). Ele o considera também como um manifesto pós-ocidental, na medida em que aponta para uma mudança radical na política do conhecimento - uma mudança que coloca o trabalho intelectual de indígenas e afro-latinos no foco de mira (2006, p.130).

São três suas observações críticas. Minhas respostas a cada uma delas não tentam fechar o debate, mas continuá-lo num diálogo rumo ao futuro. Salvatore assinala aspectos essenciais que contribuem para tornar visível a fronteira que separa os princípios dos paradigmas disciplinares (neste caso a história) e os princípios do pensamento descolonial. É precisamente por essa razão que insisto no argumento sustentado ao longo de La idea de América Latina, de que o pensamento descolonial é uma opção (descolonial) de coexistência (ética, política, epistêmica). Não de coexistência pacífica, mas de conflito que reclama o direito de re-existência em todas as ordens do pensar e do viver, como magnificamente o mostrou e argumentou Adolfo Achinte Albán (2007).

1) Para Salvatore um dos maiores méritos do livro é abrir o caminho e estabelecer os fundamentos para a exploração da "colonialidade" no terreno do conhecimento e da subjetividade, isto é, “da geo-política do conhecimento" (2006, p. 132). Não obstante, para Salvatore, esse argumento apresenta uma visão limitada da "colonialidade" posto que privilegia categorias, conceitos e visões de mundo sobre outras "formas mais comuns de dominação colonial” (p. 132), das quais entendo que Salvatore se refere ao controle colonial econômico e político. De modo que, se a "colonialidade" sustenta Salvatore -é "a estrutura lógica da dominação colonial”, não fica claro quais são as rela- 
ções entre essas e as formas de dominação, exploração e exclusão na esfera da produção e reprodução, e no espaço público. Depois de explicar com mais detalhe sua primeira objeção, Salvatore conclui essa seção sustentando que, de certo modo, minha posição acaba sendo dual: de um lado, estaria somente a epistemologia moderna ocidental e, de outro, a pluriversalidade, somente as vozes e as posições dos damnés (Alban Achinte,2007, p. 133).

Sobre o primeiro ponto, devemos considerar dois níveis de argumentos: um primeiro que já foi explorado no projeto modernidadecolonialidade-descolonialidade, e um segundo relativo à parte que destaco no argumento de La idea de América Latina. Posto que o objetivo de meu argumento era compreender como a idéia da América Latina chegou a se constituir, e não explicar a lógica da colonialidade em relação a outras opções (disciplinares, ideológicas, políticas, éticas, epistêmicas), parece óbvio que a explicação do surgimento e consolidação de uma idéia acentue as categorias, os conceitos, as visões de mundo e a filosofia do conhecimento.

Além das publicações e intervenções públicas recentes de vários membros do projeto, na América Latina e na Europa, ${ }^{2}$ é importante notar, nas explorações descoloniais do duo modernidadecolonialidade, dois momentos. O primeiro momento, iniciado por Aníbal Quijano, e já referido em La idea de América Latina, introduziu a noção de padrão colonial de poder (em meu vocabulário "matriz" em vez de "padrão"). Quijano (como sociólogo ligado à economia, a partir da teoria da dependência) enfatizou as seguintes esferas: o controle da economia (apropriação de terras e recursos naturais; exploração do trabalho) e o controle da autoridade (formas de governo, controle militar). Definiu o eurocentrismo não em termos geográficos, mas em termos epistêmicos e históricos:

2 Ver, por exemplo, a obra recente de Heriberto Cairo e Walter Mignolo (2008). Ver também a primeira parte de uma longa entrevista realizada por Marina Grzinic (2008), onde explico as relações entre as quatro esferas da matriz colonial do poder. Nessa entrevista, o objetivo era explicar a matriz colonial de poder e não apresentar como nasceu a idéia da América Latina, ela mesma (a idéia) sendo parte da formação e transformação da matriz colonial do poder. de controle do conhecimento e da subjetividade. Isto é, colonialidade do saber e do ser. Caracterizou o pensamento descolonial como o desprendimento do eurocentrismo como esfera do conhecimento, a partir do qual é possível controlar a economia, a autoridade, o gênero e a sexualidade, em suma, a subjetividade.

Santiago Castro-Gómez (filósofo), em um segundo momento, se ocupou em esclarecer as relações, na matriz colonial de poder, entre a dominação material (economia, autoridade, instituições) e a dominação epistêmica. Castro-Gómez (2005), dialogando com as teses principais de Edward Said, presentes em Orientalismo (1978), destaca a importância fundamental do conhecimento no controle da subjetividade e, por conseqüência, no controle da economia e a autoridade. Contudo, essas premissas já estavam em andamento antes de 1978, no diálogo complexo travado, entre finais dos anos 60 e dos anos 70, entre a teoria da dependência, a filosofia da liberação e a teologia da liberação. Em suma, a matriz colonial deixa para trás o legado da distinção entre estrutura e superestrutura e destaca as complexas inter-relações nas esferas da matriz colonial de poder: a idéia da América Latina que tem como horizonte imperial o controle da economia e a autoridade (aqui entram os conflitos e interesses imperiais da França frente aos Estados Unidos), o controle do conhecimento, o controle da subjetividade dos sujeitos coloniais, o controle do gênero e da sexualidade mediante o modelo de família cristã-colonial, latifundiária e burguesa, e da normatividade sexual.

2) A segunda observação de Salvatore se refere à História (escrita com maiúscula) e a colonialidade (escrita em itálico). Para Salvatore, meu argumento segue o de Frank e Wallerstein, na medida em que situo o começo do sistema-mundo capitalista no século XVI, ao mesmo tempo em que localizo, no século XVI, o surgimento de uma constelação de poder (por exemplo, a matriz colonial), estruturada com duas faces de peso desigual: a modernidade e a colonialidade. Em realidade, eu não sigo nem um nem outro ponto, o que já está claro em meu livro Historia Locales/Diseños Globales 
(2003). ${ }^{3}$ A objeção de Salvatore provém, aqui, de um mal entendido, provavelmente devido aos limites postos pelos editores da coleção Manifestos. A dupla face da mesma moeda, modernidadecolonialidade, está explicada principalmente num artigo monográfico publicado em inglês (Mignolo, 2007a) e que também será publicado em castelhano em 2008. Salvatore se pergunta e questiona as relações que estabeleço entre a invasão castelhana em Tawantinsuyu e Anahuac e a invasão dos Estados Unidos no Iraque. Como pode sustentar-se que a lógica da colonialidade se mantém através de tantas mudanças na História?

A resposta é a seguinte: em primeiro lugar, muda a retórica da modernidade. No século XVI, a retórica salvacionista da modernidade enfatizava a conversão ao cristianismo. Mais adiante, a partir do século XVIII, a salvação é pensada em termos de conversão à civilização (secular). Após a Segunda Guerra Mundial, a retórica salvacionista da modernidade celebra o desenvolvimento como condição da modernização. Isso permanece até hoje, na quarta etapa, depois da queda da União Soviética, agora com ênfase na tríade desenvolvimento, democracia e mercado. Mudaram também as relações de produção e o controle da economia: do monopólio mercantil ao livre comércio; da revolução industrial à revolução tecnológica, etc. Mudaram também as relações de autoridade (controle político): os espanhóis saíram da América do Sul; os ingleses da América do Norte e em seguida da Índia; os franceses da África do Norte, etc. Enfim, mudaram "os conteúdos", mas não os "termos da conversa" (a lógica da colonialidade). Mudaram as ênfases nos domínios da matriz colonial de poder (da ênfase no controle das almas passa-se ao controle dos corpos - a eugênica - e ao controle das carteiras - a sociedade de consumidores). Porém o que não mudou foram dois dos elementos fundamentais da matriz colonial de poder. Por um lado, mantém-se a dispensabilidade da vida humana (a acumulação e a autoridade vêm em primeiro lugar,

${ }^{3}$ No mesmo ano de 2003, este livro foi traduzido para o português, no Brasil, pela Editora da Universidade Federal de Minais Gerais (UFMG), com o título Histórias locais/Projetros globais. e depois disso, se possível, algo é feito para que as pesssoas não morram; também é necessário eliminar, de diferentes maneiras e através de várias vias, aqueles que atentam contra a ordem econômica e de autoridade). Por outro lado, também se mantêm as quatro esferas inter-relacionadas da matriz colonial de poder (economia, autoridade, gênero e sexualidade, conhecimento e subjetividade), mediante o controle do conhecimento, que é, ao mesmo tempo, racista e patriarcal. Esses são elementos que não mudaram, desde o discurso cristão do século XVI ao discurso secular e economicista do século XXI: no caso do Iraque, o objetivo final era o controle da economia (já conseguido através da presença das oito companhias petroleiras ocidentais que assinaram contratos de longo prazo no país) e do conhecimento (o qual foi e será difícil; melhor dito, impossível). Desse modo, meu objetivo não é comparar a conquista da América com a invasão do Iraque, mas conectar dois momentos históricos na trajetória e na transformação da matriz colonial do poder: estamos ainda no mesmo horizonte, embora a economia deslocasse a hegemonia da teologia e a teoria secular do estado dos séculos precedentes.

3) Na terceira observação, Salvatore começa a dialogar com seus fantasmas mais do que com os argumentos de La idea de América Latina. Esse é um tema sobre o qual Salvatore também gerou sólidos e importantes trabalhos. ${ }^{4} \mathrm{E}$ é um tema também sobre o qual colaboramos na organização de dois seminários, um em Duke e o outro na Universidad Torcuato Di Tella, em Buenos Aires. É um tema delicado, no qual é comum que o fantasma se levante cada vez que alguém que não é negro nem índio, ou que é homem e heterossexual, invoca o menosprezo epistemológico a que estão submetidos e submetidas pessoas identificadas com tais configurações sociais. O fantasma comum

${ }^{4}$ Ver o artigo de Salvatore (1998) sobre a representação do império informal dos Estados Unidos na América Latina, que foi em seguida desenvolvido num magnífico livro (2006). Ver, também, vários dos trabalhos de um dos seminários que co-organizamos, publicado em Nepantla. Views from South. Local versus Imperial Knowledge: reflections on Hiram Bingham and the Yale Peruvian Expedition, v.4, n.1, 2003. Disponivel em: http:/ /muse.jhu.edu/journals/nepantla/toc/nep4.1.html. 
(até Zizek conseguiu vê-lo) é o do "privilégio epistêmico" e o da "política de identidade". Assim, Salvatore, depois de levantar objeções que, como digo, são brigas com moinhos de vento mais que com meu argumento, sentencia:

Não considero a idéia de privilégio epistêmico totalmente convincente. Tampouco acho que uma comunidade de determinada localidade seja capaz de controlar e de manter para si mesma sua própria perspectiva, conhecimento ou categorias. O conhecimento local, assim como qualquer outro tipo de bens, está sujeito à apropriação por estranhos (Salvatore, 2006, p.136).

Antes de entrar nesse parágrafo, é necessário dissipar outros mal-entendidos. Salvatore acha que, em meu argumento, privilegio certos autores "que são representantes de raças ou povos oprimidos por séculos de colonialismo [...] é muito difícil de engolir” (p. 136). ${ }^{5}$ Por quê? pergunta-se Salvatore: "Estariam os textos de um sociólogo boliviano escrito em quechua mais em sintonia com as necessidades dos oprimidos do que os textos de outro sociólogo boliviano escrito em castelhano, ou inclusive que de um sociólogo europeu escrito em inglês ou francês?’(p. 137).

Sem dúvida, Salvatore tem razão. E não são essas as coisas e posições as que eu defendo ou destaco em meus argumentos. Em primeiro lugar, já tornei explícito que o único privilégio epistêmico é o da modernidade, o mesmo privilégio que Salvatore defende nesses argumentos. ${ }^{6} \mathrm{O}$ privilégio epistêmico da modernidade é o que gera e mantém a colonialidade do saber e do ser. Salvatore tem razão, mas não acerta o alvo. Esse não é o meu ponto central.

Primeiramente, Salvatore está reagindo frente à possibilidade de que um sociólogo indígena es-

${ }^{5}$ Entre os autores que Salvatore diz que privilegio, estão Arturo Ardao e Bolívar Echevarría. Na verdade, não privilegio nem um nem outro, mas, ao contrário. Ardao é uma referência importante, posto que tem importantes trabalhos sobre a idéia da América Latina. É simplesmente uma referência acadêmica. Com Bolívar Echevarría, pelo contrário, me situo na calçada frontal. Parece-me que Salvatore considera que privilegio todo autor que menciono ou cito.

${ }^{6}$ Atendendo a objeções semelhantes, já faz alguns anos, escrevi um artigo no qual levanto tais argumentos (Mignolo, 2002). E, mais recentemente, estendi e concentro o argumento, distinguindo entre política de identidades e identidade na política (2007b). creva em castelhano (e não do direito que tem, por exemplo, Pierre Bourdieu de escrever em francês, e não em bretão ou em árabe, posto que os franceses colonizaram o Magreb). Assim, Nina Pacari, advogada quechua, ativista e ex-ministra de relações exteriores do Equador; e Féliz Patzi Paco, sociólogo aymara, e ex-ministro de Educação e Cultura nos primeiros anos do governo de Evo Morales, não têm privilégio epistêmico, mas, simplesmente o direito epistêmico de argumentar por seus interesses, da mesma maneira que mestiços e crioulos o fazem e o fizeram pelos seus. ${ }^{7}$ Isso não quer dizer que Pacari ou Patzi Paco “representem” todos os indígenas. Essa é a premissa cega do pensamento imperial, tanto na metrópole como nas colônias. Realmente, não representam ninguém, mas apenas colocam sobre o tapete uma opção: a opção descolonial, a opção de pensar e intervir, tanto em termos políticos como epistêmicios, que lhes foi negada (racismo epistêmico), e continua ainda sendo negada pelo privilégio epistêmico da modernidade. Como Pacari e Patzi Paco não representam aos indígenas, não esperam tampouco que todos os indígenas se unam a suas propostas, ainda que elas sejam propostas avançadas, pensadas e sentidas a partir da ferida colonial indígena, da mesma maneira como as de Bourdieu são propostas que surgem de um intelectual branco e francês, “comprometido" com a causa dos indigentes. Isso também pode ser aplicado a Bartolomé das Casas.

Há pouco conversávamos em Amsterdã com Kwame Nimako, a propósito da presença e das intervenções feitas por Robert Blackburn numa conferência sobre questões de escravidão e emancipação que teve lugar esses dias e a uma de suas seções a que assistimos juntos. Como todos e todas participantes eram brancos e brancas, perguntei a Kwame (originário de Ghana) - já terminada a

\footnotetext{
Ver os textos de Nina Pacari, La incidencia de la participación política de los pueblos indígenas: un camino irreversible, e de Felix Patzi, Sistema comunal una propuesta alternativa al sistema liberal, presentes em: Cairo e Mignolo (2008). Patzi, por exemplo, pensando tanto política como economicamente a partir da memória e da experiência colonial do ayllu, retoma e põe em questão as teses de Nikolas Luhman, que pensa a sociedade a partir da memória e a experiência da
} modernidade ocidental. 
seção e gozando do bom clima de Amsterdã nesses dias - qual era a diferença entre as teses de Robert Blackburn e sua crítica à escravidão e as do cientista político e o Primeiro Ministro de Trindade e Tobago, Eric Williams, que publicou em 1944 seu livro clássico Capitalismo e Escravidão. Como o título o indica, Williams, ademais de ser negro, era marxista. E essa era, em realidade, a questão chave da minha pergunta. A resposta dada por Kwame foi curta, porém contundente: "Blackburn, como é branco, necessita do marxismo para criticar a escravidão; Williams, em troca, não necessita”. Igualmente como Fanon, Williams "sabia" que os legados da experiência escravista e o racismo anti-negro, no mundo de hoje, vão muito além do marxismo. Não se trata, pois de um "privilégio epistêmico", mas do direito que têm os intelectuais e ativistas negros de não continuar sendo traduzidos e representados por honestos intelectuais brancos.

Assim, como dizia anteriormente, Pacari e Patzi Paco não representam os indígenas, mas fazem propostas baseadas na experiência de nações sem estado, da mesma maneira que os crioulos e mestiços fizeram suas propostas e construíram o estado moldado a seus interesses, e que eu também (filho de imigrantes italianos) tenho o direito de me alinhar com as propostas de Pacari, Patzi Paco ou Williams, e não com as de Blackburn ou Bourdieu. Essa é, simplesmente, uma das teses fundamentais presentes em La idea de América Latina, no que concerne às relações entre identidade e epistemologia e identidade e política.

Os três pontos e observações levantados por Salvatore são bastante relevantes para continuar esclarecendo que o pensamento descolonial e o pensamento epistêmico e político crítico, no paradigma da modernidade, coexistem, mas cada um tem seu norte, sua orientação, seus objetivos. Em vista disso, a geopolítica e a corpo-política do conhecimento são fundamentais, e, por isso, a monotopia da aparente diversidade epistêmica, nas ciências sociais, é, em verdade, uma monotopia que se estendeu em volta do globo, seguindo a expansão econômica e política do Ocidente.

Esses pontos se relacionam com as observações e objeções levantadas por Marcel Velázquez Castro (2008) em sua resenha, publicada em Crítica y Emancipación. Essa resenha, como a de Salvatore, é cuidadosa e rigorosa. Apresenta com clareza e honestidade os argumentos. Como Salvatore, Velázquez Castro levanta também suas dúvidas sobre alguns de meus argumentos ou presunções. A principal, que merece atenção e clarificação, é a seguinte:

Apesar dos evidentes sinais da vitalidade do pensamento descolonial na conjuntura atual, é difícil aceitar a ruptura epistemológica celebrada por Mignolo. Essas novas formas de pensar estão realmente fora do capitalismo global? Não estamos convertendo determinados subalternos e a sua perspectiva nos novos agentes privilegiados do futuro e na única maneira de ler a realidade? Para se enfrentar com êxito as formas de dominação do capitalismo global, é necessário desvincular o marxismo do projeto descolonial? Qual seria o diálogo possível entre os movimentos de emancipação que surgem no centro do sistema-mundo e o projeto descolonial? Como em todos os livros de Mignolo, as perguntas se multiplicam porque sua aventura radical de pensar sempre confunde e perturba seus leitores (Velásquez Castro, 2008, p. 163).

Não se pode responder a esse pacote de perguntas, todas elas cruciais para o projeto descolonial, em umas poucas páginas nem em uns poucos dias. As perguntas são marcas de um processo e um debate em andamento, que nos levarão a transitar por várias décadas. O que segue nada mais é que um passo a mais nesse processo, no qual tento contribuir a elucidar o que está em jogo nas perguntas e nos meus argumentos que as suscitam. Vamos, pois, por partes.

Reconhecida a vitalidade do pensamento descolonial em geral - e não em minha versão particular-, esse reconhecimento acompanha as dúvidas expressas nas perguntas. Primeira dúvida: essas novas formas de pensar estão realmente fora do capitalismo global? O pensamento descolonial, em sua fundação histórico-filosófica, não surge fora, mas sim na exterioridade: ou seja, o pensa- 
mento de alguém que foi classificado (a) fora (anthropos, bárbaros, primitivos, inferiores, homossexuais, lésbicas), no processo epistêmico político de definir o que está dentro (humanidade, civilização, desenvolvimento, heterossexual, branco ou branca, cristão ou cristã, europeu ou européia, ou crioulo [a], mestiço[a] de descendência européia na América do Sul, Austrália, Nova Zelândia, Estados Unidos, Canadá). Esse argumento já foi desenvolvido extensamente em outros lugares e debates (2008a, 2008b). Por exemplo, nos casos de Guamán Poma de Ayala e Ottobah Cugoano, escravo liberto, ambos se declaram cristãos, e é a partir de sua assunção do cristianismo, articulado na experiência e na memória indígena e africana, respectivamente, que fazem críticas devastadoras à cristandade européia. Ao fazê-lo, ambos produzem tratados políticos descoloniais que, por certo, não foram reconhecidos como tal pelos especialistas em Maquiavel, Hobbes, Locke, etc. No pensamento fronteiriço, como método, e na opção descolonial, como horizonte, é assumido que não há o "fora", mas que o pensamento surge da exterioridade (a criação do fora pelo dentro), isto é, na fronteira. Mas uma fronteira na qual os dois lados não estão em igualdade de condições. Daí a diferença epistêmica e ontológica colonial a partir da qual reclamam seus direitos epistêmicos (e não seu privilégio) aqueles que foram deixados de fora do jogo e das decisões. Hoje, Evo Morales tornou visível uma continuidade histórica em que as nações indígenas mantiveram não sua "pureza e essência índia”, já que nunca houve índios até que o discurso dominante Europeu impusesse essa denominação a aymaras, quechuas, chiquitanos, tojolabales, zapotecos, iroquíes, etc... Mas sim o que foi mantido pelos povos indígenas é a diferença, sua rejeição à assimilação e seu direito à diferença. Justamente porque não está fora do capitalismo global é que Evo Morales tem os problemas que tem com os latifundiários de Santa Cruz. ${ }^{8}$

A sua segunda pergunta é a seguinte: não

${ }^{8}$ Para mais detalhes, ver Racism and Human Rights, 6 de junho de 2008, no blog: Disponível em: http:// waltermignolo.com/2008/06/06/racism-and-humanrights. estamos convertendo determinados subalternos e a sua perspectiva nos novos agentes privilegiados do futuro e na única maneira de ler a realidade? A pergunta é similar a quando se pergunta se o copo, com a metade de líquido, está meio cheio ou meio vazio. Em primeiro lugar, hoje estamos vivendo na perspectiva de agentes privilegiados do passado e do presente. Em segundo lugar, a opção descolonial, e por isso é uma opção e paradigma de co-existência, rejeita sempre uma única maneira de ler a realidade, seja esta cristã, liberal ou marxista. ${ }^{9}$ Esses pensamentos totalizantes, criadores de totalidade, estão em conflito com o pensamento fronteiriço e a opção descolonial. Como expliquei no debate citado (Mignolo, 2008b), Vélazquez Castro pensa, assumindo a objetividade sem parênteses e a partir da perspectiva que coloca, e eu também penso com a mesma lógica que ele. Porém a opção descolonial, a opção de coexistência, é um pensamento que assume a objetividade entre parênteses: creio no que creio e defendo o que creio, e entendo que frente à minha postura há outra posição equivalente de alguém que defende suas crenças, mas sabe que a sua não é a "única maneira de ler a realidade". Esse é o espaço do diálogo pluri-versal. Frente a ele se encontram os espaços uni-versais, os pensamentos que assumem a objetividade sem parênteses - que há uma única maneira de ler a realidade e que temem quando alguém não a aceita, não está de acordo ou a desafia. Aqui está a fratura epistemológica onde se gestarão os projetos epistêmicos, políticos e éticos do século XXI. A pergunta parecia apontar para o temor do pensamento hegemônico, moderno e pós-moderno, que poderia perder seu privilégio a partir do momento em que os subalternos começam a pensar por si mesmos, sem esperar a orientação do maestro.

A terceira pergunta é a seguinte: Para en-

${ }^{9}$ Aqui há outro nó por desamarrar. No Islã, certos atores sociais assumem a objetividade sem parênteses, reproduzindo, em outras palavras, a lógica imperial do ocidente que enfrentam. Mas, por outro lado, há tendências e atores sociais que traçam já um tipo de pensamento fronteiriço e uma opção descolonial, ainda que não usem essas expressões. O lema é Olha o que fazem e não como o chamam. Não olhe o que dizem, mas o que fazem. 
frentar-se com êxito às formas de dominação do capitalismo global é necessário desvincular o marxismo do projeto descolonial? Remeto-me novamente à anedota e conversa com Kwame Nimako a propósito de Eric William e Robert Blackburn. Minha resposta à pergunta é um contundente sim. Isso não nega o marxismo, mas o vê provinciano. "Enfrentar com êxito o capitalismo global" requer mais que outro projeto também global e universal, como o capitalismo, que já mostrou, em variadas ocasiões, que o marxismo pode ser um espaço de dissidência, mas não pode competir dentro da mesma lógica apenas invertendo os conteúdos. Na medida em que a opção descolonial não propõe uma ideologia universal (como o liberalismo, o cristianismo ou o marxismo, todas elas formando parte do globo do Show de Truman), enfrentála com êxito significa e implica multiplicar e conectar projetos descoloniais globais. Simplificando: se distinguimos entre o Ocidente e o resto ("the West and the rest"), deixando de lado todas as zonas intermediárias, aquilo que o "resto" - o Oriente Médio, a América do Sul e o Caribe, a Ásia Central e o Cáucaso, a África do Norte e subSaariana, e mesmo a China e Japão, que não foram colonizadas como Índia, mas não escaparam das intervenções do Ocidente na primeira na Guerra do Ópio (1848) e na segunda a partir da restauração Meiji (1865) - tem em comum é ter sido tocado e supervisado, ferido ou empurrado pelo Ocidente. Cada um dos projetos de enfrentamento à matriz colonial de poder (uma de cujas esferas, a econômica, leva, no vocabulário marxista, o mote de capitalismo) se desenvolveu em distintas línguas, histórias, subjetividades, formas de organização política e econômica prévias à infiltração da matriz colonial de poder (produção de mercadorias e promoção do livre comércio, transmissão de imagens televisivas, imposição de políticas estatais nas relações internacionais, controle de relações de gênero e sexualidade, imposição e controle do conhecimento a partir das ciências sociais e as humanidades à ciência e a tecnologia, etc.). $\mathrm{O}$ "resto", que não compartilha com o Ocidente as histórias derivadas da Grécia e Roma, passando pela França, Inglaterra e Moscou (onde o Marxismo chegou ao estado), pode sem dúvida apelar a Marx e a pensadores marxistas subseqüentes, para "analisar" a formação do "capital" a partir da revolução industrial, mas eles seriam de pouca utilidade para analisar a formação da "matriz colonial do poder". Seria de menos utilidade ainda para analisar e entender outras formas de controle, como a colonialidade do saber e do ser, o controle do conhecimento e a subjetividade, esfera na qual está incluído o domínio das "religiões". Ou seja, na medida em que o marxismo mantém, da mesma forma que o "capitalismo global", o horizonte universal, e muda o conteúdo da opressão à emancipação, a opção descolonial se desprende de todo projeto totalitário, ainda que esse seja um projeto totalitário de liberação (seja o marxismo, a filosofia da liberação, ou o islamismo fundamentalista).

Em síntese, os argumentos sobre os limites do marxismo para enfrentar o "capitalismo global" são conhecidos, ainda que freqüentemente esquecidos. O líder ideológico da revolução iraniana, Ali Shariati, publicou em 1974, em seu regresso da França ao Irã, sua célebre obra Del Marxismo y otras falacias occidentales. Os intelectuais indígenas disseram também: é possível trabalhar juntos, como na presidência (Evo Morales) e na vice-presidência da Bolívia (Álvaro García Linera), mesmo que a cosmologia indígena e a cosmologia marxista sustentada pelos blancoides, no dizer de Félix Patzi Paco, compartilhem um horizonte de enfrentamento ao capitalismo global que, no entanto, marcha por caminhos paralelos. Robert Blackburn necessita do marxismo para criticar o capitalismo, porém Eric Williams e, antes dele, Fanon, não o necessita.

Já me estendi em demasia, de modo que atendo brevemente à quarta e última pergunta de Velázquez Castro: Qual seria o diálogo possível entre os movimentos de emancipação que surgem no centro do sistema-mundo e o projeto descolonial? As diferenças que existem entre movimentos e pensamentos de emancipação que surgem do centro do sistema-mundo e o projeto descolonial se dariam na medida em que os pri- 
meiros abandonem sua pretensão de se apresentarem como movimentos emancipatórios para todo o mundo (se ocupam de suas próprias coisas, por assim dizer), e na medida em que a periferia continue dependendo dos movimentos sociais e pensadores (de esquerda) para resolver os problemas locais. De fato, devemos ter em conta que, na atualidade (sobretudo com as migrações massivas do ex-Terceiro Mundo ao ex-Primeiro Mundo, ao coração da União Européia e aos Estados Unidos), surgem as periferias, políticas e epistêmicas, ao mesmo tempo em que se continuam mantendo os centros da periferia.

Não seria tão difícil, depois de tudo que o "resto" foi forçado a aprender do centro por 500 anos de formação e transformação das formas de produção e exploração do trabalho, nas minas, nas plantações nas fábricas, nos colégios, nos monastérios, nas universidades e em outros centros de investigação. Fanon fez a sugestão: a opção descolonial toca tanto o colonizado como o colonizador, ou seja, a opção descolonial propõe o desprendimento da lógica da colonialidade, de um horizonte de vida onde se vive para trabalhar, em lugar de trabalhar para viver.

Em última instância, o diálogo seria possível na medida em que os movimentos sociais, intelectuais e ativistas do centro estejam dispostos a dialogar com quem avança nos projetos descoloniais, os quais, em geral, surgiram da periferia global e na periferia interior dos centros econômicos e industriais (os seis países centrais da União Européia e Estados Unidos). É interessante notar, por exemplo, que, em minha experiência particular, o diálogo começou com ativistas, artistas, filósofos e filósofas na Eslovênia e na Espanha. ${ }^{10}$

${ }^{10}$ Ver, por exemplo, a entrevista Marina Grzinic (2008), e também Sobre pensamiento fronterizo y representación diálogo con Walter Mignolo, Bilboquet, n.8, 2007. Disponível em: http://bilboquet.es/B8/PAG/waltermignolo.html. Também os encontros e publicações sobre pensamiento descolonial organizado por Heriberto Cairo (cientista político), na Universidad Complutense de Madrid, e o primeiro volume, já mencionado que co-editamos. Isso no que me corresponde pessoalmente. Outras várias atividades estão em andamento através de outros membros do projeto modernidade-colonialidade, assim como outros projetos concorrentes, tais como o da Caribbean Philosophical Association.

\section{$* * *$}

Dois longos diálogos - mais que meras entrevistas - foram conduzidos por Mónica González García e por Antonio Lastra. González García é chilena de origem e estudante na Universidad da California en Berkeley, diretora da revista Lucero, muito conhecida entre estudantes e professores da área luso-hispânica nos Estados Unidos. Antonio Lastra é filósofo espanhol, radicado em Valencia, que co-dirige (com Javier Alcoriza) uma magnífica revista (em desenho e conteúdo): La Torre del Virrey: revista de Estudios Culturales.

Posto que aqui entramos no terreno do diálogo-entrevista, me referirei a meus interlocutores pelos seus nomes de batismo, Mónica e Antonio. Mónica editou um número especial da revista Lucero (2007), magnífico tanto em desenho como em composição, intitulado Remapeando la idea de América. A conversação durou umas seis semanas. Ela propôs fazer uma pergunta por vez, de modo que a seguinte pergunta tomava em consideração a resposta anterior. Às vezes se passavam três ou quatro dias antes de chegar a nova pergunta ou que fosse feita a nova resposta. Por isso, as perguntas são mais que perguntas, são parte do diálogo, e díficeis de resumir. Ademais, foi também um diálogo tenso em certos temas. Seleciono uma intervenção de Mónica na qual se destacam dois tópicos onde a tensão se revela. Ao reler a entrevista, encontro certas semelhanças com as tensões surgidas nas duas resenhas que comentei anteriormente.

O momento do diálogo a que me refiro gira em torno da ferida colonial e ao fato de que ela tem diferentes escalas: as conseqüências da colonialidade, do ser e do saber, foram diferentes para as populações provenientes da África, em relação às populações provenientes da Europa e para as populações já existentes em Abya Yala, no momento que chegaram europeus voluntários e africanos forçados. Eu ressaltava, no diálogo, que a ferida colonial afeta não somente a africanos e indígenas, mas também a população "branca”, em critérios locais do sul. Em La idea de América La- 
tina, menciono o célebre ensaio de H. A. Murena, O pecado original da América (1954), para ilustrar as respostas brancas à ferida colonial. Em outras ocasiões, ocupei-me de Rodolfo Kusch, cujas sólidas reflexões mostram, a cada passo, a diferença colonial do saber e do ser. Mónica reagiu ante essas reflexões dizendo:

I do not share that "white" Latin American pain that you describe because I am part of the huge number of people in this continent that have not benefited from hegemonic discourses that operate locally in every "Latin” American nation. First during the dictatorship and then, during the neo-liberal/democratic governments, in the nineties, I struggled against being completely oppressed and silenced by these hegemonic discourses (González García, 2007, p.43).

Como ocorre com freqüência, o efeito "totalidade" se impõe. Mónica confirma o que eu estava dizendo: ela se des-identifica das elites brancas do poder (durante a ditadura e o neoliberalismo dos noventa). No entanto, não reconhece pertencer a uma história, memória e sensibilidade de uma grande parte do subcontinente de descendência européia (nesse caso hispânica, González García). H. A. Murena, Rodolfo Kusch, Enrique Dussel falam da experiência da fratura da "consciência imigrante", com a qual me identifico como descendente de imigrantes italianos que chegaram à Argentina nos finais do século XIX. Coma ferida colonial (white Latin American pain), não estou falando de outra coisas que de Augusto Pinochet, Carlos Saúl Menem o a Goñi Sánchez de Losada. Nem todos os indígenas são revolucionários, nem todos os afrocaribenhos são seguidores de Frantz Fanon, nem todos os brancos sul-americanos são férreos defensores dos regimes opressivos ligados ao "capital global”. Enfim, haveria muito mais o que dizer sobre questões de racismo e gênero. Mas fica para outra ocasião. Os projetos políticos se situam em relação a como nos situamos na ordem de classificação social e como respondemos a eles (Quijano, 2000). O que é importante dizer é que, no século XXI, pensar em termos universais abstratos não tem sentido. Por isso, a opção descolonial se orienta em direção à pluri-versalidade como projeto universal.
No segundo tema dessa mesma intervenção, Mónica insiste na importância da guerra EUAMéxico e o tratado Guadalupe Hidalgo (1848) em relação à configuração histórica da latinidade. Sem dúvida, a própria idéia de latinidade, surgida na França, projetada e adaptada pelos "brancos" locais, surgiu em grande parte por essa guerra e pela expansão dos Estados Unidos em direção ao Sul. Bilbao também reage ante a esse fato. A outra parte da idéia de latinidade responde aos conflitos imperiais no interior da Europa e no projeto francês de liderar os países latinos, fato que permanece até hoje e de cuja história e legados Nicholás Sarkozy está se aproveitando: já não liderar o sul da Europa, mas sim o Mediterrâneo.

Em primeiro lugar, quando o editor de Blackwell me propôs escrever esse manifesto, a primeira coisa que me ocorreu foi ampliar o argumento, antecipado em dois trabalhos prévios sobre a definição da América Latina (Mignolo, 2000, 2004). Em segundo lugar, o pensamento descolonial pensa a história não cronologicamente, mas sim em nós de heterogeneidade históricoestrutural, que Aníbal Quijano descreveu em vários de seus escritos. Nesse caso, 1848 é a âncora de uma triangulação que envolve a França (o famoso 18 Brumário) e a liderança que assume no sul da Europa, a partir da América Latina e Estados Unidos (o tratado Guadalupe Hidalgo). Há uma sucesão de conflitos imperiais internos (França frente à Inglaterra e Alemanha), conflitos imperiais globais (França frente à expansão de Estados Unidos), e o avanço na deformação do continente Sul-Americano que, junto à África e Ásia Central, vai ficando fora da história (apud Hegel); também o surgimento de uma configuração social não existente até esse momento: a latinidade nos Estados Unidos. O pensamento descolonial pensa a partir das margens, e pensa as margens em relações imperiais-coloniais de poder. A descolonização da história narrada e do pensamento historiográfico é parte da tarefa do pensamento descolonial para avançar na opção descolonial. 
O diálogo com Antonio Lastra (2007-2008) é uma conversa em dois sentidos: entrecruzam-se pensamentos que partem de premissas, experiências, subjetividades, histórias, linguagens (não línguas, posto que nós dois falamos castelhano) diferentes. A diferença é que, no pensamento descolonial, ativa-se a lógica que une o senhor ao escravo: o escravo conhece a razão do senhor e a razão do escravo, enquanto o senhor conhece somente a razão do senhor, posto que o escravo, segundo ele, não tem "razão". Nesse caso, e voltando a uma das perguntas de Mónica, é possível estabelecer um diálogo com ativistas de Bilboquet, mas é quase um "diálogo de surdos" entre quem pensa em (não sobre, mas "em" no sentido de estar envolvido) e aqueles que pensamos na opção descolonial. No entanto, o diálogo com Antonio foi útil para que eu pudesse entender os temores, os preconceitos, as mágoas de um pensamento europeu que se fecha sobre si mesmo, como pensamento, mas tenta abranger o mundo, como conteúdo. Vejamos um caso patente desse diálogo de surdos, e do amparar-se sob a capa salvacionista de "pensadores liberais de cor", como Amartya Sen e Anthony Appiah. Ofereço somente uma amostra que se relaciona com temas debatidos. Diz Antonio:

Você nega que sua postura possa ser acusada de "essencialismo". No entanto, não crê que em todo argumentação dos estudos subalternos há sempre o risco de uma imitação fatal, neste caso, da homogeneidade? Indios, afros, mulheres de cor, gays e lésbicas, em quem você deposita a esperança de uma iniciativa, são exemplos de identidades fortes. Penso, pelo contrário, nas reflexões de outros pensadores sobre regiões descolonizadas, como é o caso de Amartya Sen a propósito da Asia ou de Anthony Appiah, a propósito da Africa, opostos à tentação de identidades e prioridades únicas. "O próprio" como você mesmo afirma em La Idea de América Latina (Mignolo, 2007, p.112-113, 134-135), pode ser entendido no sentido dessa tentação (Lastra, 2007-2008, p. 77).

Se a conversa tivesse tido lugar em um bar, cara a cara, lhe responderia: "iVamos hombre, haz tus deberes!" Mas, no âmbito acadêmico, há que tratar as insolências (talvez inclusive inconscientes) com respeito. A pergunta volta-se contra si mesma em seu ponto cego: a alegria do pensamen- to eurocentrado de acolher pessoas de cor que reproduzem o pensamento eurocentrado, como Sen e Appiah. Em política, temos o exemplo equivalente de Condoleezza Rice. Isso é tranquilizador, não se pretende puxar-lhes das orelhas nem tirar o tapete do chão. Sen e Appiah adotaram e se identificaram com a identidade disciplinar (economia, filosofia) e com o controle disciplinar do conhecimento, que - a partir desse poder identitário epistêmico - marginalizou e continua marginalizando todos e todas que não se submetem às regras do jogo. ${ }^{11}$ Em suma, eu sugeriria, em vez de Amartya Sen, Vandana Shiva e Ashis Nandy. E em vez de Anthony Appiah, sugiro a Sylvia Wynter e Lewis Gordon. Mas aposto que Antonio desconhece, conhece pouco ou não levou a sério todos aqueles que estão na genealogia de meu pensamento. Por isso, o diálogo é quase de surdos, como o diálogo entre o senhor e o escravo liberto.

Não comento a referência aos estudos subalternos porque isso não tem muito sentido neste diálogo, já que pensamento descolonial e estudos subalternos são laranjas de diferentes sítios. Porém, é importante sublinhar o seguinte: quando falamos no projeto modernidade-colonialidade, de descolonizar o conhecimento, partimos do fato de que a filosofia (ou qualquer outra disciplina tanto na instituição como nos princípios dos saberes ocidentais) pressupõe identidades fortes que não se reconhecem como tal, mas sim que se apresentam como universalidades abertas. Mas quem as controla? Não são por acaso homens brancos, cristãos e europeus quem formaram o cânon filosófico, "roubando-o" dos filósofos gregos aos pensadores árabes que os exploraram antes que os europeus? Não são os partidos políticos identidades fortes, controlados por elites identitárias, e que se pretendem democráticos e abertos? Entramos aqui, novamente, no terreno da identidade na política e na epistemologia, um âmbito de debate e trabalho para as próximas décadas.

\footnotetext{
${ }^{11}$ Ocupei-me detalhadamente desse problema, sobretudo no que se refere a Amartya Sen, faz pouco tempo, em Mignolo (2005b)
} 
Termino estas reflexões com uma anedota que atravessa todas as minhas observações anteriores. O livro The idea of Latin America (2005a) recebeu, em 2006, o prêmio Frantz Fanon outorgado pela Associação Caribenha de Filosofia. A associação foi uma iniciativa do filósofo jamaicano Lewis Gordon, com a colaboração de Padget Henry, Anthony Bogues, Cleavis Headley e Nelson Maldonado-Torres, os primeiro originários do Caribe britânico e o último de Porto Rico. Mónica o mencionou no começo de sua entrevista. Na edição castelhana, publicada por Gedisa em 2007, e utilizada por Salvatore, Velázquez Castro e Lastra, não se faz menção alguma ao fato. A Editorial Gedisa omitiu a informação na capa do livro, apesar de várias insistências de minha parte.

Minha insistência não se deveu a propósitos de promoção pessoal, mas sim pela implicação política do prêmio. Será que Gedisa omitiu a menção de um prêmio Frantz Fanon num livro sobre a idéia de América Latina por esquecimento? Se, por outro lado, estivéssemos falando de um Prêmio José Martí (que não conheço a existência e que presumo não houvesse ganho), a editorial Gedisa haveria feito alguma menção?

Em suma, talvez o resumo mais suscinto de La idea de América Latina. La herida colonial y la opción descolonial seja tanto o significado do prêmio Frantz Fanon como seu silêncio por parte da editorial Gedisa. Antonio Lastra menciona, em sua introdução ao diálogo, que o livro foi publicado pela Gedisa justamente na coleção "Biblioteca Iberoamericana", que inclui livros que Lastra menciona, como Racismo y discurso en América Latina, editado por Teun A. van Dijk, e Repensar América Latina, de Francisco Delich.

(Tradução de Breno Marqués Bringel)

(Recebido para publicação em junho de 2008) (Aceito em agosto de 2008)

\section{REFERÊNCIAS}

ALBÁN ACHINTE, A. Tiempos de zango y de guampín: transformaciones gastronómicas, territorialidad y reexistencia socio-cultural en comunidades Afrodescendientes de los valles interandinos del Patía (Sur de Colombia) y Chota (Norte del Ecuador), siglo XX. Tese (Doctorado en Estudios Culturales) - Universidad Andina Simón Bolívar, Quito-Ecuador, 2007.

CAIRO, H.; MIGNOLO, W. (Ed). Las vertientes americanas del pensamiento y el proyecto des-colonial. Madrid: Trama Editorial / Gecal, 2008.

CASTILLO, S. Review of the idea of Latin America. The Modern Language Review, [S.l.],v.102, n.4, oct., p.11251127, 2007.

CASTRO-GÓMEZ, S. La postcolonialidad explicada a los niños. Bogotá: Ed. Universidad del Cauca; Universidad Javeriana, 2005

CUGOANO, O. Thoughts and sentiments on the Evil of Slavery. Londres: Penguin, 1999 [1786].

GRZINIC, M. Delinking epistemology from Capital and Pluri-versality. A conversation between Marina Grzinic and Walter Mignolo. Reartikulacija. Lubjama, Eslovenia, n.4, 2008. Disponible en: www.reartikulacija.org/ dekolonizacija/dekolonialnost4 ENG.html. Acesado en: 13 jun., 2008.

GONZÁLEZ GARCÍA, M. Review of the idea of Latin America. LUCERO. A Journal of Iberian and Latin American Studies, Berkely-USA, v.17, 2007.

KENT, R. B. Review of the idea of Latin America, by Walter D. Mignolo. Geographical Review, New Hampshire, v.97, n.1, enero p136-137, 2007.

LASTRA, A. Walter Mignolo y la idea de América Latina. Un intercambio de opiniones. La Torre del Virrey: revista de Estudios Culturales, Cordoba-Argentina, n.4, p.68-78, 2007-2008.

MIGNOLO, W. La opción des-colonial: desprendimiento y apertura. Un manifiesto y un caso. En: CAIRO, H.; MIGNOLO, W. (Ed.) Las vertientes americanas del pensamiento y el proyecto des-colonial. Madrid: Trama Editorial;Gecal, 2008a. p.175-209.

. Revisando las reglas del juego: conversación con Pablo Iglesias Turrion, Jesús Espasandín López e Iñigo Errejón Galván. En: CAIRO, H; MIGNOLO,W. (Ed.) Las vertientes americanas del pensamiento y el proyecto descolonial. Madrid: Trama Editorial; Gecal, 2008b, p.209-256.

Delinking: the rhetoric of modernity, the logic of coloniality and the grammar of decoloniality. Cultural Studies, Berkely, Universituy of California, v.21, n.2/3, p.449-514, 2007a. Disponíble en: www.informaworld.com/ smpp/content $\sim$ content $=$ a $776418353 \sim \mathrm{db}=\mathrm{ai} \sim$ order = page. [trad. al castellano por José Romero, Caracas, 2008. En prensa.

The decolonial option and the meaning of identity in politics. ANALES. Nueva Época, Gotemburgo, Instituto Iberoamericano, Universidad de Goteborg, n.9-10 (n.especial sobre Etnicidad en América Latina: Relatos de Colonialismo, Resistencia y Agencia), 2007b, p.43-72.

The idea of Latin America. Oxford: Blackwell, 2005a. [trad. castellano la idea de América Latina. La herida colonial y la opción decolonial, Barcelona: Gedisa, 2007].

Prophets facingside wise: the geopolitics of knowledge and the colonial difference. Social Epistemologv, Indiana: Indiana University Press, v.19, p.111-127. 2005b. Disponible en: www.duke.edu/ wmignolo/publications/ prophets\%20facing\%20sidewise.pdf. Aceso en: 02 jul., 2008 . 
Huntington's fears: latinidad in the horizon of the modern/Colonial World. In: MÉNDES, C. (Ed.) Hegemony and multiculturalism. In: INTERNATIONAL CONFERENCE OF ACADÉMIE DE LA LATINITÉ, 10th. Rio de Janeiro: Universidad Cándido Mendes; UNESCO, 2004. p.386-412. Reference texts. 2003.

. Historias locales. Diseños globales. Madrid: Akal,

The enduring enchantement: Or the epistemic privileges of modernity and where to go from here. South Atlantic Quarterly, Durhem, Duke University Press, v.101, n.4, p.927-954, 2002. http://saq.dukejournals.org/cgi/ content/citation/101/4/927 consultado el 5/06/2008.

. La colonialidad a lo largo y a lo ancho: el hemisferio occidental en el horizonte colonial de la modernidad. LANDER, E. (Ed.) La colonialidad del saber: eurocentrismo y ciencias sociales. Perspectivas latinoamericanas. Buenos Aires: CLACSO; UNESCO, 2000. p.55-86.

QUIJANO, A Colonialidad del poder y clasificación social. Journal of World-Systems Research, Warzawa, University of California, v.11, n.2, (n.Especial. "Festchrift for Immanuel Wallerstein”. 2000. p.342-386. Disponible en http://jwsr.ucr.edu/archive/vol6/number2/pdf/jwsr-v6n2quijano. pdf. Aceso en: 01 ago., 2008.

\section{NEW REFLECTIONSONTHE "IDEA OF LATIN AMERICA": the right, the left and the discolonizing option}

\author{
Walter D. Mignolo
}

This text has the specific character of debate retaken by the author caused by reviews and interviews about his book The Idea of Latin America, published in 2005. It begins demonstrating how the various narratives of the history of colonization are plural, but as they spread they become unified in global narratives of an universal character, as an effect of totality processes. For the author that diversity of silent but alive historical forces, are today exposed, without a perspective of return to the past. In this sense he speaks about the modernity/coloniality project of decolonizing knowledge, answering and deepening several paradoxical aspects forwarded by the debate of his book, as the dialogue among thoughts of emancipation and movements that appear in the center of the world system. With this he doesn't intend to close the debate, but, on the contrary, strives to update it and to move forward in those issues of non-homogeneous populations and difference from a perspective of future and from a perspective of a pluri-versalist knowledge and practices.

KEYworDs: modernity, emancipation, difference, decolonization of thought, Latin America.
SALVATORE, R. D. A post-occidentalist manifesto. A Contracorriente: revista de Historia Social y Literatura en América Latina. Raleigh, North Carolina State University. v.4, n.1, otoño, p.126-128, 2006. Disponible en: www.ncsu.edu/project/acontracorriente/fall06/Salvatore review.pdf , Aceso en: 12 jul., 2008.

Imágenes de un imperio: Estados Unidos y las formas de representación de América Latina. Buenos Aires: Editorial Sudamericana, 2006.

The enterprise of knowledge: representational machine of informal empire. En: JOSEPH, G..; LEGRAND, C.; SALVATORE, R. (Ed.) Close Encounters of empire. Writing the cultural history of US-Latin America. Durham: Duke U.P., 1998. p.69-107.

SMITH A. The wealth of nations. Chicago: The University of Chicago Press, 1976, [1776].

VELÁZQUEZ CASTRO, M. Las promesas del proyecto decolonial o las cadenas de la esperanza. A propósito de La idea de América Latina: la herida colonial y la opción descolonial de Walter Mignolo. Crítica y Emancipación revista Latinoamericana de Ciencias Sociales, [S.1.], n.1, p.255-263, jun., 2008

\section{NOUVELLESREFLEXIONSSUR “LACONCEPTIONDE L'AMERIQUE LATINE': la droite, la gauche et l'option décoloniale}

Walter D. Mignolo

Ce texte revêt un caractère spécifique de débat repris par l'auteur en fonction de rapports et d'interviews réalisés à propos de son livre The Idea of Latin America publié en 2005. Il commence en démontrant comment les narratives diversifiées de l'histoire de la colonisation sont plurielles mais, lorsqu'elles sont diffusées, elles finissent par s'unifier en narratives globales à caractère universel, comme conséquence d'un processus de totalité. Pour l'auteur, cette diversité de forces historiques silencieuses mais vivantes, apparaissent aujourd'hui sans perspective de retour en arrière. Dans ce sens-là, il parle du projet modernité/colonialité pour décoloniser la connaissance. Ceci permet de répondre et d'approfondir divers aspects paradoxaux soulevés par le débat de son livre comme le dialogue entre les mouvements et les pensées d'émancipation qui surgissent au cœur du système-monde. Il n'est pas question de conclure le débat, bien au contraire, on cherche à actualiser et à avancer dans ces questions de la différence et des populations qui ne sont pas homogènes dans une perspective d'avenir et d'une connaissance et des pratiques pluri-versalistes.

Mots-CLÉs: modernité, émancipation, différence, décolonisation de la pensée, Amérique Latine. 